\title{
Hypertensive Emergencies and Urgencies: A Clinical Guide
}

\author{
K Subba Reddy
}

\begin{abstract}
Hypertension being a common medical condition is resulting in increased hospital admissions worldwide and, moreover, hypertensive emergencies and urgencies have led to an increment in critical care patients. It is, therefore, evident that urgent diagnosis and immediate and appropriate treatment of these conditions is paramount in reducing mortality and morbidity.

Manifestations of the hypertensive emergencies and urgencies may vary depending on the target organ that is affected. Fortunately, more effective and relatively safe drugs are available, nowadays, to lower blood pressure (BP) quickly in these lifethreatening situations. Critical care physicians should be familiar with all pharmacological and clinical actions of the medications available in treating these hypertensive emergencies, along with the appropriateness of the choice of medication in any given situation.

The purpose of review is to understand the therapeutic interventions in treating a hypertensive crisis.
\end{abstract}

Keywords: Acute aortic dissection, Hypertensive encephalopathy, Left ventricular failure, Pharmacological therapy.

How to cite this article: Reddy KS. Hypertensive Emergencies and Urgencies: A Clinical Guide. Hypertens J 2015;1(1):51-56.

Source of support: Nil

Conflict of interest: None

\section{INTRODUCTION}

Systemic hypertension is a common medical condition affecting over 1 billion people in the world. Hypertensive emergencies occur in up to $2 \%$ of patients with systemic hypertension. Early recognition, evaluation and appropriate treatment are important in the management of hypertensive urgencies and emergencies to prevent excessive morbidity. ${ }^{1}$ In some clinical circumstances, immediate reduction of blood pressure (BP) is indicated, not because of its absolute level but because of coexisting complications (e.g. aortic dissection, renal failure and acute left ventricular failure) which may make any degree of hypertension dangerous. ${ }^{2}$

\section{DEFINITION}

The classification and approach to clinical hypertension have been reviewed by the Joint National Committee

\section{Consultant Intensivist}

Department of Critical Care Medicine, Apollo Critical Care Apollo Hospital, Hyderabad, Telangana, India

Corresponding Author: K Subba Reddy, Consultant Intensivist Department of Critical Care Medicine, Apollo Critical Care Apollo Hospital, Jubilee Hills, Hyderabad, Telangana, India Phone: 919989385110, e-mail: drksreddy77@yahoo.co.in
(JNC). ${ }^{3}$ Hypertensive crisis are, by convention, divided into emergencies and urgencies (Tables 1 and 2). Severe elevation of blood pressure (BP) in the presence of acute end organ damage leads to hypertensive emergency, whereas hypertensive urgencies occur without acute end organ damage. Distinguishing hypertensive urgencies from emergencies is critical in formulating the treatment plan. Patient with hypertensive urgency should have their BP reduced within 24 to 48 hours, whereas patients with hypertensive emergency should have their BP lowered immediately, but not to normal levels. The term 'malignant hypertension' has been used to describe a syndrome characterized by elevated BP accompanied by encephalopathy or acute nephropathy. ${ }^{3,4}$ This term, however, has been removed from national and international BP control guidelines and is best referred to as 'hypertensive crisis'.

\section{PATHOPHYSIOLOGICAL FACTORS}

Hypertensive crisis is thought to be initiated by an abrupt increase in systemic vascular resistance likely related to neurohumoral activation. The subsequent increase in $\mathrm{BP}$ generates mechanical stress and endothelial injury leading to increased vascular permeability, activation of coagulation cascade and deposition of fibrin resulting in vaso-occlusion. ${ }^{3}$

Patients with a hypertensive crisis frequently have thrombotic microangiopathy with severe microvascular abnormalities resulting in renal or cerebral dysfunction. Vanden born et al demonstrated increased levels of

Table 1: Certain examples of hypertensive urgencies

Severe uncontrolled (asymptomatic) hypertension

Hypertension associated with burns

Perioperative hypertension

Uncontrolled hypertension in organ transplant patients

Accelerated hypertension

Severe hypertension in patients with coronary artery disease

Table 2: Certain examples of hypertensive emergencies

Hypertensive encephalopathy

Malignant hypertension

Acute pulmonary edema

Acute stroke (hemorrhagic)

Sympathetic excess syndromes

Eclampsia

Pheochromocytoma crisis 
von Willebrand factor (VWF), VWF polypeptides, prothrombin fragment 1 (F1R2) and plasmin-antiplasmin complexes with reduced levels of ADAMTS13 in patients with a hypertensive crisis when compared with normotensive controls. Recent data suggest that endothelial dysfunction may persist for years after the onset and resolution of a hypertensive emergency. ${ }^{5,6}$

Some examples of hypertensive emergencies are hypertensive encephalopathy, acute left ventricular failure, acute aortic dissection, intracranial hemorrhage, pheochromocytoma crisis, eclampsia and substance/ drug-induced acute hypertension. Some examples for hypertensive urgencies are accelerated hypertension, severe hypertension associated with organ transplant patient, hypertension associated with burns, perioperative hypertension and severe uncontrolled hypertension.

\section{Selected Clinical Conditions}

\section{Acute Aortic Dissection}

Aortic dissection should be considered in patients presenting to the emergency department with acute chest or abdominal pain and elevated BP (Table 3). There are subtle differences between the pain caused due to aortic dissection and that of myocardial infarction. However, the pain due to dissection is abrupt in onset and is quite severe immediately, whereas patients with myocardial infarction often report a more insidious onset. Left untreated, approximately three-fourth of the patients with type A dissection (ascending aorta) die within 2 weeks of acute episodes, but with successful treatment 5 years survival rate is $75 \%{ }^{10}$ If the patient is hypertensive, $\mathrm{BP}$ should be reversed to near normal levels with a drug that causes the BP to come down smoothly rather that drastically. Direct venodilatation that reflexly stimulates the heart rate are contraindicated in aortic dissection. ${ }^{10,11}$

\section{Hypertensive Encephalopathy}

Hypertensive encephalopathy is an uncommon deadly complication of severe hypertension. Although encephalopathy occurs mainly in patients with chronic uncontrolled or malignant hypertension, it can also complicate sudden hypertension of short duration. Hypertensive encephalopathy occurs more frequently against the background of renal insufficiency than when the kidney function is

Table 3: Clinical manifestations of acute aortic dissection

Severe pain in the chest, neck or abdomen
Syncope
Sudden visual impairment
Dyspnea
Nausea/vomiting
Melena/GI-GU blood loss

normal. The full clinical manifestations of hypertensive encephalopathy may take 1 to 2 days to evolve.

Severe headache is a prominent symptom. Symptoms, such as confusion and stupor, may appear simultaneous or following the onset of headache. Other clinical features may include vomiting and visual disturbances. On physical examination, the BP is invariably elevated but there is no fixed level of BP above which encephalopathy is likely to occur. The fundi reveal generalized arteriolar spasm with exudates/hemorrhages. Papilledema is present in most patients of encephalopathy.

Patients with uncontrolled hypertension who present with severe headache and altered mental status may have hypertensive encephalopathy which, of course, must be separated from other complications of hypertension, such as cerebral infarction or hemorrhage and uremic encephalopathy. The only definitive way to confirm the diagnosis of hypertensive encephalopathy is the response of the patient's condition to immediate antihypertensive therapy.

Once hypertensive encephalopathy is diagnosed, the BP should be lowered quickly, yet the diastolic BP should probably remain at or slightly above $100 \mathrm{~mm} \mathrm{Hg}$. Rapid treatment of severe hypertension produces prompt, dramatic and significant relief of symptoms of hypertensive encephalopathy. The goal of therapy is to prevent permanent neurologic damage. In this regard, continuous $\mathrm{BP}$ monitoring is often very useful.

\section{Cerebrovascular Accidents}

Most of the patients with cerebral ischemia present with high BP regardless of subtype of infarct or pre-existing hypertension. The elevated BP may be a protective physiologic response to maintain cerebral perfusion pressure in the ischemic area. ${ }^{9}$ The American stroke association and European stroke guidelines recommend treating hypertension if systolic BP is more than $220 \mathrm{~mm} \mathrm{Hg}$ or diastolic BP is more than $120 \mathrm{~mm} \mathrm{Hg}$ in patients who are not undergoing thrombolytic therapy for acute ischemic strokes but BP control in patients due for thrombolytic therapy is different, i.e. to maintain systolic $\mathrm{BP}<185$ $\mathrm{mm} \mathrm{Hg}$ or diastolic BP $<110 \mathrm{~mm} \mathrm{Hg}$. For intracranial hemorrhage patients presenting with systolic BP 150 to $220 \mathrm{~mm} \mathrm{Hg}$ and without contraindication for acute lowering of $\mathrm{BP}$ target, lowering the systolic BP to $140 \mathrm{~mm} \mathrm{Hg}$ is safe and can be useful for improving functional outcomes.

\section{Pheochromocytoma Crisis}

Blood pressure is markedly elevated during paroxysm and patient may have profound sweating, marked tachycardia, pallor, numbness, tingling and coldness of the feet and hands. If pheochromocytoma is suspected, alpha adrenergic blocking drug phentolamine should be 
given in a dose of 1 to $5 \mathrm{mg}$ intravenously, and repeated in few minutes if needed. A beta blocking drug may be useful if the patient has concomitant cardiac arrhythmia. A combined alpha and beta blocker like labetalol can also be used. ${ }^{12}$

\section{Sympathetic Crisis}

Most commonly seen are related to the use of drugs, such as amphetamines, cocaine and phencyclidine. Rarely, these crises may be seen with pheochromocytoma, patients receiving a monoamine oxidase inhibitor who ingest tyramine containing food, or patients who suddenly stop antihypertensive medications, such as clonidine or beta adrenergic antagonists.

For hypertension associated with cocaine use, treat with benzodiazepines and avoid beta blocker therapy. ${ }^{14}$

\section{Eclampsia}

Hypertension is one of the most common medical disorders affecting pregnancy. Even though delivery of the fetus is the definitive treatment for pre-eclampsia and eclampsia, therapies like volume expansion, magnesium sulphate for seizure prophylaxis and hypertension control are pivotal. Loading dose of $-4 \mathrm{gm}$ iv, followed by a constant infusion of 1 to $2 \mathrm{gm} /$ hour. American college of obstetricians and gynecologists recommends keeping systolic BP between 140 and $160 \mathrm{~mm} \mathrm{Hg}$ and diastolic BP between 90 and $105 \mathrm{~mm} \mathrm{Hg}$. Pre-eclampsia and eclampsia patients may have very labile $\mathrm{BP}$, hence, it is better to monitor their BP more closely.
Hydralazine has been recommended as a drug of choice to treat severe pre-eclampsia and eclampsia. However, hydralazine has a number of properties that make it unsuitable for this indication. Its side effects are common and mimic symptoms of worsening pre-eclampsia. This drug can cause precipitous fall in BP compromising maternal cerebral perfusion pressure and uteroplacental blood flow. Angiotensin-converting-enzyme (ACE) inhibitors and angiotensin receptor blockers (ARBs) should be avoided because of fetal or placental toxicity. Diuretics are avoided because of the volume-depleted state in pre-eclampsia. ${ }^{15}$

\section{Acute Pulmonary Edema (Left Ventricular Failure)}

Severe hypertension may cause acute left ventricular failure. Higher the BP, harder the left ventricle must work. Decreasing the work load of the failing myocardium should improve cardiac functions. In acute pulmonary edema, myocardial oxygen demand increases because of increased end diastolic fiber length and high left ventricular volume. Nitroglycerin sublingual or intravenous (IV) continuous drip, enlaprilat IV and frusemide IV are the agents generally used in treating hypertension with acute pulmonary edema.,

\section{Pharmacologic Agents used in the Treatment of Hypertensive Emergencies}

The pharmacologic agents used in the treatment of hypertensive emergencies are discussed in Table 4.

Table 4: Parenteral drug options of hypertensive emergencies

\begin{tabular}{|c|c|c|c|c|c|c|}
\hline Drug & Dose & Administration & $\begin{array}{l}\text { Onset of } \\
\text { action }\end{array}$ & $\begin{array}{l}\text { Duration of } \\
\text { action }\end{array}$ & Adverse effects & Indications \\
\hline Labetalol & $\begin{array}{l}20-80 \mathrm{mg} \text { IV } \\
\text { bolus every } \\
10 \text { mins; } 2 \mathrm{mg} / \\
\text { min infusion }\end{array}$ & $\begin{array}{l}\text { IV bolus } \\
\text { IV infusion }\end{array}$ & 5 minutes & 3-6 hours & $\begin{array}{l}\text { Nausea, vomiting, } \\
\text { bronchospasm, heart } \\
\text { block, orthostatic } \\
\text { hypotension }\end{array}$ & $\begin{array}{l}\text { Most hypertensive } \\
\text { emergencies except heart } \\
\text { failure }\end{array}$ \\
\hline $\begin{array}{l}\text { Sodium } \\
\text { nitroprusside }\end{array}$ & $\begin{array}{l}0.25-10 \\
\mu \mathrm{g} / \mathrm{kg} / \mathrm{min} ; \\
\text { maximal dose } \\
\text { is } \leq 10 \text { minutes }\end{array}$ & IV infusion & $\leq 30$ seconds & $1-2$ minutes & $\begin{array}{l}\text { Hypotension, nausea, } \\
\text { vomiting, muscle } \\
\text { twitching, } \\
\text { thiocyanate and cyanide } \\
\text { intoxication, methemo- } \\
\text { globinemia }\end{array}$ & $\begin{array}{l}\text { Most hypertensive } \\
\text { emergencies; caution } \\
\text { with renal and hepatic } \\
\text { insufficiency and high } \\
\text { intracranial pressure }\end{array}$ \\
\hline Hydralazine & $\begin{array}{l}10-20 \text { mg IV; } \\
10-50 \text { mg IM }\end{array}$ & $\begin{array}{l}\text { IV infusion } \\
\text { IM injection }\end{array}$ & 10-20 minutes & 4-12 hours & $\begin{array}{l}\text { Reflex tachycardia, } \\
\text { headache, nausea, } \\
\text { vomiting, aggravation of } \\
\text { angina }\end{array}$ & $\begin{array}{l}\text { Eclampsia; caution with } \\
\text { high intracranial pressure }\end{array}$ \\
\hline Nitroglycerin & $5-100 \mu \mathrm{g} / \mathrm{min}$ & IV infusion & 2-5 minutes & 3-5 minutes & $\begin{array}{l}\text { Headache, nausea, } \\
\text { vomiting, tolerance with } \\
\text { prolonged use }\end{array}$ & Coronary insufficiency \\
\hline Enalaprilat & $\begin{array}{l}1.25-5 \mathrm{mg} \\
\text { every } 6 \text { hours }\end{array}$ & IV infusion & $10-15$ minutes & $6-24$ hours & $\begin{array}{l}\text { Hypotension, } \\
\text { renal failure }\end{array}$ & $\begin{array}{l}\text { Acute left ventricular } \\
\text { failure }\end{array}$ \\
\hline Esmolol & $\begin{array}{l}\text { 50-200 mcg/ } \\
\mathrm{kg} / \mathrm{min}\end{array}$ & IV infusion & $\begin{array}{l}\text { Rapid }< \\
1 \text { minute }\end{array}$ & $\begin{array}{l}10-12 \\
\text { minutes }\end{array}$ & $\begin{array}{l}\text { Hypotension, } \\
\text { bradycardia, faintness, } \\
\text { blurred vision }\end{array}$ & $\begin{array}{l}\text { Severe hypertension in } \\
\text { patients with tachycardia, } \\
\text { coronary syndromes, and } \\
\text { perioperative hypertension }\end{array}$ \\
\hline
\end{tabular}




\section{Labetalol}

Labetalol is a combined selective alpha adrenergic and beta adrenergic receptor blocker with an alpha to beta blocking ratio of 1:7. Labetalol is metabolized by the liver to form an inactive glucuronide conjugate. ${ }^{23}$ The hypotensive effect of labetalol begins within 2 to 5 minutes after its IV administration, reaching a peak at 5 to 15 minutes following administration, and lasting for about 2 to 4 hours. Due to its beta-blocking effects, the heart rate is either maintained or slightly reduced. Unlike pure beta adrenergic blocking agents that decrease cardiac output, labetalol maintains cardiac output. Labetalol reduces the systemic vascular resistance without reducing total peripheral blood flow. ${ }^{26}$ In addition, the cerebral, renal, and coronary blood flows are maintained. This agent has been used in the setting of pregnancy-induced hypertensive crisis, because little placental transfer occurs mainly due to the negligible lipid solubility of the drug. ${ }^{27}$ Labetalol may be administered as loading dose of $20 \mathrm{mg}$, followed by repeated incremental doses of 20 to $80 \mathrm{mg}$ at 10 minutes intervals until the desired BP is achieved. Alternatively, after the initial loading dose, an infusion commencing at 1 to $2 \mathrm{mg} / \mathrm{min}$ and titrated up to until the desired hypotensive effect is achieved. Bolus injections of 1 to $2 \mathrm{mg} / \mathrm{kg}$ have been reported to produce precipitous falls in $\mathrm{BP}$ and should, therefore, be

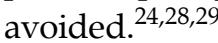

\section{Esmolol}

Esmolol is an ultrashort acting cardioselective beta adrenergic blocking agent. ${ }^{34}$ The onset of action is within 60 seconds, with duration of action of 10 to 20 minutes. The metabolism of esmolol is via rapid hydrolysis of ester linkages by red blood cell (RBC) esterases and is not dependent on renal or hepatic function. Due to its pharmacokinetic properties, some authors consider it an 'ideal adrenergic blocker' for use in critically ill patients. This agent is available for IV use both as a bolus and as an infusion. Esmolol is particularly useful in severe postoperative hypertension. Esmolol is a suitable agent in situations in which cardiac output, heart rate and BP are increased, and is administered as a 0.5 to $1 \mathrm{mg} / \mathrm{kg}$ loading dose over 1 minute, followed by an infusion starting at 50 $\mathrm{mcg} / \mathrm{kg} / \mathrm{minutes}$ and increasing up to $300 \mathrm{mcg} / \mathrm{kg} / \mathrm{min}$ as necessary. ${ }^{30-33}$

\section{Calcium Channel Blockers}

Clevidipine is third generation experimental dihydropyridine (CCB) with ultrashort acting selective arteriolar vasodilator properties. ${ }^{19}$ It has been studied in the setting of cardiac surgery and is being developed for the treatment of hypertensive emergencies in the emergency department due to its ability to be titrated having a halflife less than a minute. ${ }^{20}$ The velocity trial demonstrating efficacy in the emergency setting is currently pending publication. Nicardipine has an onset of action of 5 to 10 minutes, and can be titrated at 15 minutes intervals. It has been found to be safe and effective in neurologic hypertensive emergencies as well as other conditions, and has a favorable effect on myocardial oxygen balance increasing both stroke index and coronary blood flow. ${ }^{25}$ Nifedipine use (10 mg orally) is discouraged in hypertensive emergencies, except possibly in patients with severe pre-eclampsia. ${ }^{12,15-17}$

\section{Direct Vasodilators}

Until recently, nitroprusside has been the most commonly used drug for hypertensive emergencies because of rapid onset and its almost universal efficiency. ${ }^{21}$ However, its use has been decreasing because of awareness of its toxicity and the need for invasive monitoring. It remains the agent that should be considered when other agents fail, and can be added to other agents, such as esmolol allowing for a lower less toxic dose. ${ }^{21}$ Nitroglycerin is a weak arterial dilator (requiring high doses), but is recommended as a first line agent in the treatment of heart failure and acute coronary syndromes due to its favorable effects on coronary blood flow and cardiac workload. Its hypotensive effects are due to a reduction of preload and cardiac output, making it a poor choice in other hypertensive emergencies. ${ }^{35}$

\section{Other Agents}

Clonidine has a unique role in hypertensive emergencies for the patient who recently stopped taking the drug, inducing a rebound hypertension. It can be given orally $0.2 \mathrm{mg}$ in this setting, or a clonidine patch can be used for patients unable to take oral medications. ${ }^{22}$ Its effects begin at 30 to 60 minutes, and peak effects are seen at 2 to 4 hours. Fenoldopam is a unique peripheral dopamine receptor agonist, and has a role in renal and neurologic related hypertensive emergencies. ${ }^{15,18}$ Phentolamine has been used successfully in cocaine related hypertensive emergencies and pheochromocytoma. ${ }^{13,14}$ Enalaprilat, the only available IV ACE inhibitor, has special application in patients with heart failure or acute coronary syndrome, but caution should be exercised because of common first dose hypotension. Administration of enalaprilat also has been recommended as a diagnostic maneuver to determine the contribution of high renin to the patient's $\mathrm{BP}^{12}$ 
Hypertensive Emergencies and Urgencies: A Clinical Guide

\section{CONCLUSION}

A fundamental therapeutic goal in the management of hypertensive emergencies/urgencies is to attain a safe level of BP quickly while minimizing the risk of unwanted hypotension. Most patients with uncontrolled hypertension are either noncompliant to therapy or have previously undiagnosed hypertension. Severe hypertension is associated with significant morbidity and, therefore, should be treated promptly. Long-term prognosis of patients with severe hypertension depends on good control of hypertension.

An important clinical decision is whether the patient's degree of hypertension requires immediate reduction of $\mathrm{BP}$ and hospital care. The choice of parenteral or oral antihypertensive drugs depends on the clinical evaluation, available laboratory data and facilities. The level to which BP needs to be lowered depends on the clinical diagnosis but not just the degree of hypertension. In patients with evidence of acute dysfunction/damage of target organs, it is best to provide hospital care, preferably in an intensive care unit. For less urgent situations, treatment can be given as an outpatient basis with close follow-up. Asymptomatic patients with normal clinical/laboratory findings can be managed in the emergency department and follow-up visits. Indiscriminate utilization of parenteral antihypertensive drugs should be avoided. With immediate therapeutic reduction of BP, cardiac, renal, and neurological parameters should be closely monitored. Upon the resolution of a hypertensive emergency/urgency, long-term management strategy should be outlined to prevent recurrence of the acute problem and to preserve target organ function in the long run by effectives and sustained control of hypertension. Based on clinical assessment and laboratory values, workup for secondary hypertension may be indicated in some patients with hypertensive crisis.

\section{REFERENCES}

1. Hajjar I, Kotchen TA. Trends in prevalence and awareness, treatment and control of hypertension in the United States, 1998-2000. JAMA 2003;290(2):199-206.

2. Ram CV, Silverstein RL. Treatment of hypertensive urgencies and emergencies. Curr Hypertens Rep 2009 Oct;11(5):307-314.

3. The sixth report of the Joint National Committee of Prevention, detection, evaluation and treatment of high blood pressure. Arch Intrem Med 1997;157(21):2413-2446.

4. Marik PE, Rivera R. Hypertensive emergencies: an update. current opinion critical care 2011;17(6):569-580.

5. Ault MJ, Elldrodt AG. Pathophysiological events leading to the end organ effects of acute hypertensions. Am J Emerg Med 1985;3(6 suppl):10-15.

6. Wallach R, Karp RB, Reves JG, Oparil S, Smith LR, James TN. Pathogenesis of paroxysmal hypertension developing during and after coronary bypass surgery; a study of hemodynamic and humoral factors. Am J Cardiol 1980;46(4):559-565.

7. Fromm RE, Varon J, Gibbs L. Congestive heart failure and pulmonary edema for the emergency physician. J Emerg Med 1995;13(1):71-87.

8. Gandhi SK, Powers JC, Nomeir AM, Fowle K, Kitzman DW, Rankin KM, Little WC. The pathogenesis of acute pulmonary edema associated with hypertension. N Engl J Med 2001;344(1):17-22.

9. Strandgaard S, Olesen J, Skinhoj E, Lassen NA. Auto regulation of brain circulation in severe arterial hypertension. BMJ 1973;1(5852):507-510.

10. Khan IA, Nair CK. Clinical, diagnostic, and management perspectives of aortic dissection. Chest 2002;122(1):311-328.

11. Estrera AL, Miller CC, Safi HJ, Goodrick JS, Keyhani A, PoralEE, Achouh PE, Meada R, Azizzadeh A, Dhareshwar $\mathrm{J}$, et al. Outcomes of medical management of acute type B aortic dissection. Circulation 2006;114:1384-1389.

12. Blumenfeld JD, Laragh JH. Management of hypertensive crises: the scientific basis for treatment decisions. Am J Hypertens 2001;14:1154-1167.

13. Hollander JE. The management of cocaine associated myocardial ischemia. N Engl J Med 1995;333(19):1267-1272.

14. Hollander JE, Carter WC, Hoffman RS. Use of phentolamine for cocaine induced myocardial ischemia. N Engl J Med 1992;327(5):361.

15. Marik, PE, Varon J. Hypertensive Crises: Challenges and Management. Chest 2001;131(6):1949-1962.

16. Scardo JA, Vermillion ST, Newman RB, Chauhan SP, Hogg BB. A randomized, double-blind, hemodynamic evaluation of nifedipine and labetalol in pre-eclamptic hypertensive emergencies. Am J Obset Gynecol 1999;181(4):862-866.

17. Vermillion ST, Scardo JA, Newman RB, Chauhan SP. A randomized, double-blind trial of oral nifedipine and intravenous labetalol in hypertensive emergencies of pregnancy. Am J Obset Gynecol 1999;181(4):858-861.

18. Bodmann KF, Troster S, Clemens R, Schuster HP. Hemodynamic profile of intravenous fenoldopam in patients with hypertensive crisis. Clin Investig 1993;72(1):60-64.

19. Rodriguez G, Varon J. Clevidipine: a unique agent for the critical care practitioner. Crit Care Shock 2006;9(2):37-41.

20. Ericsson H, Tholander B, Regardh CG. In vitro hydrolysis rate and protein binding of clevidipine, a new ultrashort-acting calcium antagonist metabolized by esterases, in different animal species and man. Eur J Pharm Sci 1999;8(1):29-37.

21. Friederich JA, Butterworth JF. Sodium nitroprusside: twenty years and counting. Anesth Analg 1995;81(1):152-162.

22. Houston MC. Treatment of hypertensive emergencies and urgencies with oral clonidine loading and titration. A review. Arch Intern Med 1986;146(3):586-589.

23. Lund-Johansen P. Pharmacology of combined alpha and beta_blockade:II. Haemodynamic effects of labetalol. Drugs 1984;28(suppl 2):35-50.

24. Kanot J, Allonen H, Kleimola T, Mantyla R. Pharmacokinetics of labetalol in healthy volunteers. Int J Clin Pharmacol Ther Toxicol 1981;19(1):41-44.

25. Goldberg ME, Clark S, Joseph J, Moritz H, Maguire D, SeltzerJL, Turlapaty P. Nicardipine versus placebo for the treatment of postoperative hypertension. Am Heart J 1990;119:446-450.

26. Pearce CJ, Wallin JD. Labetalol and other agents that block both alpha and beta adrenergic receptors. Cleve Clin J Med 1994;61(1):59-69. 
27. Marx PG, Reid DS. Labetalol infusion in acute myocardial infarction with systemic hypertension. Br J Clin Pharmacol 1979;8(suppl 2):233-238.

28. Olsen KS, Svendsen LB, Larsen FS, Paulson OB. Effect of Labetalol on cerebral blood flow, oxygen metabolism and autoregulation in healthy humans. Br J Anaesth 1995;75(1): 51-54.

29. Rosei EA, Trust PM, Brown JJ, Lever AF, Robertson JIS. Intravenous labetalol in severe hypertension. Lancet 1975;306(7944):1093-1094.

30. Gray RJ. Managing critically ill patients with esmolol: an ultra-short-acting beta adrenergic blocker. Chest 1988; 93(2):398-403.

31. Lowenthal DT, Porter RS, Saris SD, Bies CM, Slegowski MB, Staudacher A. Clinical pharmacology pharmacodynamics and interactions with esmolol. Am J Cardiol 1985;56(11): 14F-18F.

32. Reynolds RD, Gorczynski RJ, Quon CY. Pharmacology and pharmacokinetics of esmolol. J Clin Pharmacol 1986;26(suppl A):A3-A14.

33. Balser JR, Martinez EA, Winters BD, Perdue PW, Clarke AW, Huang W, Tomaselli GF, Dorman T, Campbell K, LipsettP, et al. Beta-adrenergic blockade accelerates conversion of postoperative supraventricular tachyarrhythmias. Anesthesiol 1998;89(5):1052-1059.

34. Platia EV, Michelson EL, Porterfield JK, Das G. Esmolol versus verapamil in the acute treatment of atrial fibrillation or atrial flutter. Am J Cardiol 1989;63(13):925-929.

35. Stumpf JL. Drug therapy of hypertensive crises. Clin Pharm 1988;7(8):582-591. 